\title{
Leaching losses of soil applied potassium fertiliser in pineapple(Ananas comosus)cultivation on tropical peat soils in Malaysia
}

\begin{abstract}
With good drainage systems, some vegetables, horticultural crops, plantation crops, and rice have been successfully grown on both temperate and tropical peat soils. In Malaysia, pineapple (Ananas comosus) is mainly grown on peat soils. However, most of the potassium (K) fertiliser recommendations are made without satisfactory quantification of the total $\mathrm{K}$ uptake in relation to the distribution of $\mathrm{K}$ in pineapple parts. Loss of $\mathrm{K}$ through leaching has also not been properly investigated although its retention in peat soils is low. This preliminary study was carried out to determine the efficiency using applied $\mathrm{K}$ under a conventional recommended fertilisation programme in pineapple cultivation with in situ residue burning (before replanting). Results showed that most of the $\mathrm{K}$ uptake in pineapple can be found in fruit, stems, and leaves. However, the general trend of $\mathrm{K}$ distribution was in the order of: fruits $>$ leaves $>$ stem $>$ peduncle $>$ crown $>$ roots. $\mathrm{K}$ recovery in pineapple cultivation was $36 \%$, and this low recovery was attributed to leaching. $\mathrm{K}$ losses through leaching in pineapple cultivation on tropical peat soils needs to be taken into account in fertiliser recommendations for efficient recovery of $\mathrm{K}$. This is important because it is not possible to build up the $\mathrm{K}$ content of peat soils by saturating the exchange complex. (C) The Royal Society of New Zealand 2006.
\end{abstract}

Keyword: Pineapple; Potassic fertiliser; Potassium leaching; Tropical peat soil 